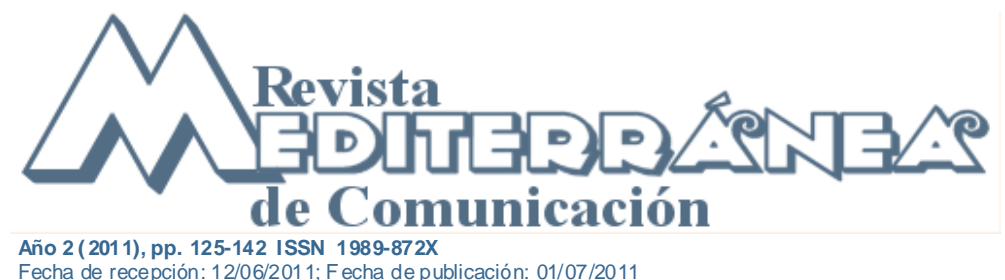

\title{
La llegada del offset a la prensa de Canarias: implicaciones en el tratamiento de la imagen
}

\section{The arrival of the offset printing system to the press in the Canary Islands: implications in the image treatment}

\author{
Alberto Ardèvol Abreu \\ DEA de la Universidad de La Laguna. España. \\ alber@ ardevol.es
}

\section{Resumen}

El presente artículo forma parte de un trabajo de investigación más extenso sobre la evolución de la fotografía de prensa en Canarias desde el período 1975-1980 hasta la primera década del siglo XXI. Durante la segunda mitad de la década de 1970 se produjo en el archipiélago, de manera paulatina, la transición del sistema de impresión tipográfica al sistema offset. A través de estas páginas pretendemos analizar la influencia que tuvo en la fotografía de prensa de las islas la llegada de este nuevo sistema de impresión, que mejoró de manera significativa la calidad física de los periódicos del archipiélago. La impresión offset, mucho más limpia que su predecesora tipográfica, se publicitaba en Inglaterra bajo el lema "We don't print on your hand, we print on paper" (no imprimimos en sus manos, imprimimos el papel). Los cambios se llevaron a cabo de forma muy gradual, casi imperceptible en un primer momento, coincidiendo, además, con los años de transición política, y trajeron consigo modificaciones en la serie visual no lingüística (fotografías, dibujos, color...), as í como en los restantes elementos del periódico, desde el formato al diseño, pasando incluso por los contenidos. Los resultados obtenidos se basan en el muestreo sistemático de dos de las cabeceras más importantes en aquellos momentos en las islas: El tinerfeño El Día y el vespertino Diario de Las Palmas.

\section{Abstract}

This article is part of a more extensive research on the evolution of press photography in the Canary Islands from the period 1975-1980 up to the first decade of the 21st century. In the second half of the 1970s it took place in the archipelago a gradually transition from the typographic printing system to the offset printing system. In these pages we try to analyze the influence that the arrival of this new printing system had in the photography of press of the islands, which improved in a significant way the physical quality of the Canarian newspapers. The offset printing system, much cleaner than the ancient typographic system, was advertised in England under the slogan "We do not print on your hand, we print on paper " These changes in the printing systems was done gradually, in an almost imperceptible way initially, coinciding with the years of the political transition, and brought modifications in the non-linguistic visual series (photographs, illustrations,

Forma de citar este artículo: Ardèvol Abreu, Alberto (2011) "La llegada del offset a la prensa de Canarias: implicaciones en el tratamiento de la imagen", en Revista Mediterránea de comunicación, 2, pp. 125-142. Recuperado el día de mes de año (añadir enlace) 
color ...), as well as in the remaining elements of the newspapers, from the format up to the design and contents. The results that we present are based on the systematic sampling of two of the most important Canarian newspapers at the time: El Día and the evening newspaper Diario de Las Palmas.

\section{Palabras claves}

Fotoperiodismo; fotografía; offset; tipografía; Canarias; España.

\section{Key Words}

Photojournalism; photography; offset; tipographic printing system; Canary Islands; Spain.

Sumario: 1. Introducción. 1.1. Offset frente a tipografía. 1.2. La fotografía en la impresión tipográfica y en offset. 1.3. Canarias y la transición al offset. 2. Metodología. 2.1. Variables analizadas. 3. Resultados. 3.1. Cambios de formato. 3.2. Número de fotografías publicadas. 3.3. Tamaño de las imágenes. 3.4. Géneros utilizados. 3.5. Actualidad de las fotografías. 3.6. Procedencia de las fotos. 3.7. Fotoperiodismo / fotoilustración. 3.8 Representación visual de otras realidades geográficas. 3.9. Color. 4. Conclusiones. 5. Bibliografía. 6. Notas.

Summary: 1. Introduction. 1.1. Offset against tipographic printing system. 1.2 Photography in the tipographic printing system and in the offset. 1.3. Canary Islands and the transition to offset. 2. Method. 2.1. Analyzed variables. 3. Results. 3.1. Changes in the format. 3.2. Number of published photographs. 3.3 Size of the images. 3.4. Used genres. 3.5. Age of the photograph. 3.6. Origin of the photographs. 3.7. Photojournalism / photoillustration. 3.8. Visual representation of other places. 3.9. Color. 4. Conclusions. 5. Bibliography. 6. Notes.

\section{Introducción}

"La foto es una mirada subjetiva de un fotógrafo y de un diario que la publica" (Vilches, 1993: 244).

La historia de la fotografía en la prensa es relativamente breve, si la comparamos con la historia de la prensa en sí. Si bien es cierto que el uso de grabados no fotográficos en las páginas de los periódicos es muy anterior (en España, los llamados "avisos" del siglo XVII llevaban en ocasiones grabados alusivos al texto (Rodríguez y Gómez, 2003), la colocación de imágenes fotográficas arranca en los años 70 del siglo XIX en Estados Unidos y 3 décadas después en España, con el periódico Abc. Yanes (2003: 183-184) ha encontrado algunas fotografías en prensa tinerfeña (muy esporádicas) a mediados de la década de los noventa del siglo XIX, impresas "con técnicas artesanales merced a clichés suministrados por personajes de la vida pública o artistas foráneos para anunciar su actuación".

Las mejoras en los procesos técnicos de la fotografía ${ }^{1,}$ así como los progresos en la impresión de las imágenes en tiradas más o menos grandes, permitieron una progresiva introducción de la imagen fotográfica en el periódico. Pero no basta con la posibilidad técnica de hacer buenas fotos y con que éstas puedan imprimirse con cierta facilidad: 
hace falta, además, una cultura visual de los periodistas y de los gestores de los periódicos, que deben apostar por la imagen. Una apuesta que se hizo de manera muy progresiva hasta la llegada del offset, y de manera mucho más rápida a partir de la introducción de esta nueva técnica de impresión. Explicaremos a lo largo de esta exposición cómo tuvo lugar esta evolución en nuestro archipiélago, haciendo hincapié en los años de transición al offset, que, además, vienen a coincidir con los años de transición política en España.

\subsection{Offset frente a tipografía}

Suele hablarse de la llegada del sistema offset como una revolución en el periódico en general, y en fotoperiodismo en particular ${ }^{2}$. Nosotros consideramos que, en el contexto canario, esta nueva tecnología supuso importantes mejoras en la calidad de la imagen, pero no supuso una revolución, al menos de manera inmediata. Y es que los cambios en periodismo se producen habitualmente de manera gradual, y no basta sólo con que haya una tecnología para romper inercias y configurar nuevas realidades ${ }^{3}$.

Para comprender la importancia de los cambios tecnológicos que se produjeron en la prensa de los años 70, es necesario conocer algunos aspectos de la composición, reproducción e impresión en tipografía y en offset. De manera resumida, podemos decir que la impresión tipográfica se produce cuando el papel entra en contacto con una plancha, normalmente de plomo, en la que los elementos que se van a transferir al papel se encuentran en relieve e impregnados en tinta (impresión directa y en relieve): la composición se hace en plomo, con tipos móviles sueltos o en línea (estos últimos elaborados con la linotipia). En el sistema offset, en cambio, el papel entra en contacto con un cilindro de caucho que previamente se ha impregnado con tinta, procedente de una plancha de zinc o aluminio que ha sido tratada mediante un proceso fotoquímico (por eso se habla de impresión indirecta y plana). En este sistema se habla de composición fría, de fotocomposición, actualmente integrada con la tecnología informática. La fotocomposición vino a reducir enormemente el trabajo necesario para componer los textos y para insertar imágenes. Como su nombre indica, "se basa en emplear matrices transparentes con los signos y letras [y las imágenes] que se trasladan fotografiados a la película o papel fotográfico" (Zurita, 2003). La llegada del sistema offset supuso la gradual salida del plomo ${ }^{4}$ de los talleres de impresión.

La impresión con el sistema tipográfico era muy lenta y trabajosa, pues empezaba con la composición de las páginas en la caja, con la ayuda de la linotipia, y terminaba con la impresión en la rotativa, pasando por la confección de la teja, que era un molde curvado de plomo que se ajustaba a los rodillos impresores, y que se construía a partir de la página compuesta en la caja. Con el nuevo procedimiento, ya no se hacía necesaria la teja.

Como decíamos, la impresión en el sistema offset no se produce por contacto entre la plancha y el papel, sino que entre ambos se intercala un cilindro revestido de caucho, que es impregnado por la plancha y que, a su vez, impregna al papel. Además de la mayor calidad de impresión y la rapidez del proceso, otra ventaja es que las sucesivas impresiones, al ser un procedimiento indirecto, no empeoran la calidad de impresión: en el 


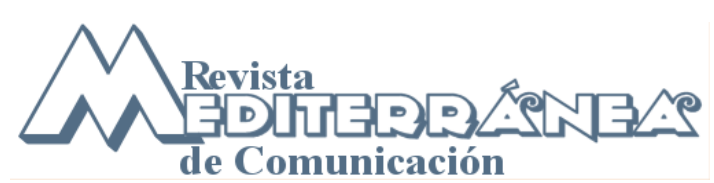

ISSN 1989-872X - Año2 (2011), pp. 125-142

sistema tipográfico, esto se producía por el desgaste del plomo, que entraba en contacto con el papel (De Pablos, 1993: 82-83).

\subsection{La fotografía en la impresión tipográfica y en offset}

En tipografía, para colocar una fotografía o una imagen en la plana se hacía necesario confeccionar un fotograbado. El fotograbado pasó a la historia con la llegada del offset.

Es falso que la técnica de fotograbado (con la impresión tipográfica) no permita la reproducción de fotografías de calidad. El resultado final va a depender más de la calidad del proceso y de la calidad del papel que de la técnica empleada. Así, por ejemplo, encontramos que, en la década de los 50, en el Diario de las Palmas se reproducían con mucha frecuencia en la primera página y en la última, imágenes fotográficas de enorme calidad y gran tamaño. Éstas se imprimían en imprenta tipográfica a través del proceso de fotograbado. $Y$ encontramos fotos de $15 \times 20 \mathrm{~cm}$. e incluso mayores, en un número aceptable si consideramos el número de páginas del periódico (solía oscilar entre 12 y 14): algunos días encontrábamos más de 15 fotografías. Como ejemplo, en la primera del domingo día 24 de mayo de 1953 (fecha muy anterior a las que aquí estudiamos) podemos observar 5 imágenes a gran tamaño del Roque Nublo, así como de restos cerámicos del Museo Canario o una imagen del busto del doctor Gregorio Chil, elaboradas por el taller de fotograbado Ascanio. Estas bellas portadas desaparecieron al año siguiente, sustituyéndose por otras con fotograbados de baja calidad. Por tanto, ni gran tamaño ni buenas calidades van a ser patrimonio exclusivo del offset. Ni siquiera el color, pues a pesar de lo complejo del proceso, se llegaron a imprimir libros en color con la técnica de la tipografía.

\subsection{Canarias y la transición al offset}

Pero, ¿cómo se produjo la transición de la tipografía al offset en el archipiélago canario? Los periódicos de las islas no se quedaron precisamente rezagados en la aplicación de las nuevas tecnologías. Acirón ${ }^{5}$ recuerda la llegada del offset como un acontecimiento de gran importancia para la fotografía de prensa:

[La impresión offsef] significa una revolución que permite publicar un mayor número de fotografías, el ahorro de tiempo con el consiguiente ahorro económico. Anteriormente, para publicar una fotografía, se llevaba a cabo un proceso lento, que con esta nueva tecnología se aceleró mucho, y este avance significó una revolución en tiempo y en cantidad de fotografías para publicarse.

A principios de los años 70 comenzaría a introducirse en los talleres tipográficos del archipiélago la nueva tecnología de impresión. Pocos años más tarde Diario de Avisos y El Día ya imprimían en estas nuevas rotativas, mientras La Tarde, sin abandonar la linotipia, introdujo la fotocomposición, con una tecnología intermedia que permitía procesar planchas fotopolímeras en su rotativa tipográfica (Zurita, 2003: 18). El Día, en concreto, cambió la rotativa tipográfica por otra offset el 14 de septiembre de 1975, 
aunque ya venía ensayando el nuevo sistema de impresión con anterioridad con el suplemento especial de los domingos.

En Diario de Las Palmas (y también en La Provincia), en cambio, la transición se llevaría a cabo unos años más adelante. Podemos hablar, por tanto, de una transición "en dos tiempos" en las principales cabeceras del archipiélago. El 16 de mayo de 1980 sale a la calle el primer ejemplar del vespertino Diario de Las Palmas que se tira en offset. El 10 de junio de ese mismo año saldría en offset (tirado en la misma rotativa) La Provincia: la rotativa que sustituiría a la vieja Marinoni tipográfica fue encargada a la firma de maquinaria pesada Creusot-Loire y construida en Nantes (Francia):

Diseñada en base al modelo Gazette Super, es una de las más modernas y completas rotativas litográficas (sistema offset) disponibles en la actualidad, e incorpora las técnicas más avanzadas de automatización y controles electrónicos para impresiones de alta calidad ${ }^{6}$.

En cuanto al diseño, se conservan las 6 columnas por página (aunque se emplean también las columnas compuestas, que configuran páginas de 4 columnas). El periódico offset empieza a venir en un solo volumen, con las 32 páginas juntas. Anteriormente, por las limitaciones de la rotativa tipográfica, el periódico se ofrecía "fasciculado", en forma de 4 tomos de 8 páginas cada uno.

\section{Método}

Nuestro corpus de análisis lo formaron dos cabeceras, una editada en Santa Cruz de Tenerife y otra en Las Palmas de Gran Canaria. Hablamos de los periódicos El Día y del vespertino Diario de Las Palmas. El universo de análisis estaba constituido por las fotografías encontradas el mes anterior y el siguiente a la llegada de la impresora offset en cada uno de los diarios mencionados: agosto y octubre de 1975 para El Día y abril y junio de 1980 para Diario de Las Palmas. Se trata de 105 ejemplares en total, 54 de El Día y 51 de Diario de Las Palmas. Los ejemplares se consultaron en hemeroteca de la sala de Canarias de la Biblioteca General y de Humanidades de la Universidad de La Laguna. Al ser un universo muy amplio, realizamos un muestreo sistemático y aleatorio, revisando seis ejemplares de cada periódico por mes, correspondientes a cada uno de los días de la semana (El Día no se tiraba los lunes y Diario de Las Palmas los domingos, por eso en una semana se tiraban 6 ejemplares), seleccionados al azar, e incluyendo los suplementos encontrados ${ }^{7}$. En total, se analizaron 966 fotos; 420 de El Día y 546 del Diario de Las Palmas. Estas fotografías fueron posteriormente clasificadas por géneros ${ }^{8}$, y el tratamiento estadístico se llevó a cabo con el programa SPSS para Windows.

La dificultad del análisis comparativo radica en que los dos periódicos estudiados cambiaron de sistema de impresión con 5 años de diferencia, así que no tendría mucho sentido comparar directamente los resultados obtenidos para El Día con los hallados para Diario de Las Palmas, puesto que habría que tener en cuenta otros factores además del sistema de impresión. Hemos utilizado una metodología muy similar a la empleada para nuestro trabajo sobre inmigración en la fotografía de prensa de Canarias (Ardèvol, 2008). La herramienta de análisis de las fotografías incluidas en piezas informativas ha sido la técnica del análisis de contenido 


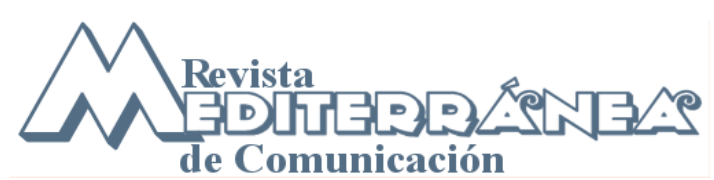

Para acercarnos a la dimensión humana de aquellos años de transición tecnológica y política, así como para conocer de cerca el trabajo en los talleres de los periódicos, utilizamos además métodos cualitativos. Llevamos a cabo tres entrevistas en profundidad: con Juan Hernández, fotograbador, fotógrafo y estereotipista en El Día durante casi 50 años (en su domicilio, en junio de 2010); con Antonio García Rueda, fotógrafo que trabajó para Efe, El Día y el Ayuntamiento de La Laguna en los años 60, 70 y 80 (en su domicilio, en julio de 2010) y con Ricardo Acirón Royo, catedrático de Periodismo de la Universidad de La Laguna (en la Facultad de Ciencias de la Información, en marzo de 2010).

\subsection{Ficha de análisis}

Se procedió a la construcción de variables a través del programa SPSS, que serían previamente recogidas en una ficha. De cada imagen seleccionada, se recogió:

\section{a.- Datos de identificación básicos.}

- Cabecera a la que pertenece: El Día, Diario de Las Palmas o alguno de sus suplementos. Encontramos un suplemento dominical de El Día, un suplemento del sábado del Diario de Las Palmas y un suplemento del viernes del Diario de Las Palmas denominado La Cultura.

- Fecha de publicación.

b.- Indicadores sobre el emplazamiento de la imagen en la página y en el periódico.

- Página.

- Ubicación en la página: superior, media, inferior; central, de entrada, de salida.

- Disposición de la imagen: vertical u horizontal.

- Número de columnas.

- Superficie de la imagen.

c.- Origen y protagonistas de la foto.

- Atribución: ninguna, agencia, agencia fotográfica, fotógrafo, archivo, cedida. Las agencias empleadas por estos periódicos fueron Europa Press y Efe. En El Día encontramos nombres propios de fotógrafos como Enrique Martín, Juan Antonio de Juan, Emilio Hernández, Juan Hernández, Benítez, Pedro Díaz, Domingo Acosta Pérez, Gustavo Armas, Paco, G. P., J. A. Padrón Sabina, Tomás Ayut, Morales, J. A. Padrón Albornoz. En Diario de Las Palmas se publicaban imágenes de Juan Santana, Juan Gregorio. Álamo Montañés, Juan Cubas, José A. Mejías, Perdicero, José Manuel Santana, A. C. S. y P. Calabuig.

- Lugar donde se tomó la imagen: insular, provincial, regional, nacional, internacional, desconocida.

- Protagonista de la imagen: persona, paisaje natural, paisaje urbano, animal, objeto.

d.- Características "técnicas" de la imagen".

- Técnica empleada: tipografía con célula fotoeléctrica, tipografía con fotograbado, offset.

- Uso del color: monocromo, bitonos, cuatricromía.

- Lineatura (líneas / centímetro).

- Profundidad de campo: muy poca, intermedia, mucha, no valorable.

- Plano: gran plano general, plano general, plano entero, planos cortos, primer plano, plano detalle.

e.- Composición y noticiabilidad

- Imagen recuadrada o no. 
- Pie de foto: sin pie; titulado, no titulado; informativo, interpretativo, opinativo.

- Actualidad de la foto: día anterior, dos días antes, una semana o menos, más de una semana, desconocida.

- Relación de la imagen con el tema tratado: nula, vaga, fuerte, total.

- Género fotográfico: las clasificamos, siguiendo a Abreu (1998) en géneros informativos (fotonoticia, reportaje, ensayo), subgéneros informativos (noticia, reportaje, entrevista, reseña, encuesta, crónica), géneros opinativos (editorial, foto mancheta, foto parlante, fotomontaje, caricatura fotográfica), subgéneros opinativos (editorial, comentario / artículo).

Muchas de las variables no se han utilizado para este estudio, pero se utilizarán en posteriores trabajos.

Para construir las variables asociadas a las unidades de análisis hemos empleado un procedimiento mixto, deductivo e inductivo. En un primer momento creamos las variables y los valores basándonos en nuestra experiencia investigadora, en función de lo que pensábamos encontrar. Posteriormente, pasamos la ficha de análisis con estas primeras variables y valores a un $20 \%$ de la muestra, desechando variables no pertinentes e incluyendo otras variables y valores que no habíamos considerado en un principio.

\section{Resultados}

Para poder valorar la incidencia real de la llegada del nuevo sistema de impresión en los periódicos publicados en Canarias, consideramos que habría que realizar, junto con este estudio, otro con una muestra de periódicos publicados un año y cinco años después.

\subsection{Cambios de formato}

El cambio de rotativa impuso, en las cabeceras estudiadas, un cambio de formato (medidas del papel que empleaba la rotativa). Así, en el caso de El Día, el papel sobre el que se imprimía la cabecera pasó de medir aproximadamente $82.9 \times 55.8 \mathrm{~cm}$. (no la página, sino la sábana completa) a ocupar $62.8 \times 46.2 \mathrm{~cm}$., una considerable reducción de tamaño. También en Diario de Las Palmas se impuso el cambio de formato del papel, pero en sentido inverso: la nueva rotativa exigía un formato algo mayor. De los $61.4 \times 47.3$ $\mathrm{cm}$. que se empleaban se pasó a $66.6 \times 48.8 \mathrm{~cm}$. Este cambio se produce de manera radical: la nueva máquina rotativa no admite el formato anterior y el mismo día en que se comienza a tirar en offset el cambio es patente. Por tanto, el 14 de septiembre de 1975 para El Día y el 16 de mayo de 1980 para el Diario de Las Palmas son las fechas en que se produce el cambio de formato.

\subsection{Número de fotografías publicadas}

En ambos periódicos se produjo un aumento considerable en el número de fotos en un mes (aunque el hecho de muestrear sólo un mes nos hace considerar los datos con cautela). Así, en los 6 ejemplares analizados en El Día antes de que llegara el offset se publicaron 176 fotografías, mientras que en los 6 ejemplares analizados después hallamos 244, a pesar que la media de páginas por ejemplar antes y después era de 32 (esto supone casi un 39\% de incremento en un solo mes). Algo similar ocurrió 5 años después en Diario de Las Palmas: en los 6 ejemplares estudiados antes de la llegada del 
nuevo sistema de impresión encontramos 244 fotos, y en los 6 impresos en offset, 302, lo que supone casi un $24 \%$ de aumento.

\subsection{Tamaño de las imágenes}

Según nuestro estudio, El Día (excluido aquí su suplemento dominical, pues ya tiraba en offset a modo de prueba en agosto de 1975) ubicaba fotos de algo más de $105 \mathrm{~cm}^{2}$ de media (y una desviación típica de 61.93) antes de la llegada del offset. Diario de Las Palmas (excluidos también sus suplementos del sábado y el suplemento cultural) ofrecía, como media, imágenes de unos $102 \mathrm{~cm}^{2}$ (y desviación típica de 58.79): éstas últimas son imágenes más pequeñas que en El Día, a pesar de que habían transcurrido 5 años (la muestra de El Día es de agosto de 1975 y la de Diario de Las Palmas de abril de 1980). La llegada del offset supuso (al menos en un principio), una ligera reducción en el tamaño de las imágenes de El Día, pues el periódico tinerfeño redujo su media hasta $93 \mathrm{~cm}^{2}$ (y desviación típica de 104.69), mientras que Diario de Las Palmas aumentó muy discretamente hasta los $103 \mathrm{~cm}^{2}$ (y desviación típica de 58.46). Las pruebas estadísticas no permiten afirmar que exista una relación sólida entre la variable "superficie" y la variable "sistema de impresión" (prueba de chi-cuadrado de Pearson; $\alpha \leq 0,05$, pero los residuos tipificados corregidos $< \pm 1,96)$.

\subsection{Géneros utilizados}

Siguiendo a Abreu (1998), podemos llevar a cabo una clasificación de las fotos publicadas por géneros. Distingue Abreu los géneros periodísticos fotográficos informativos (entre los que cita la fotonoticia, el reportaje, la crónica y el ensayo) de los opinativos (que incluyen la foto editorial, la foto mancheta, la foto parlante, el fotomontaje y la caricatura fotográfica). En estos géneros, la fotografía representa el eje en torno al que se articula la noticia: la imagen lleva el peso, mientras que el texto la complementa. Si, por el contrario, el texto lleva el peso de lo relatado, mientras que la foto es un complemento, Abreu considera a la imagen como subgénero, y habla entonces de subgéneros periodísticos fotográficos informativos y opinativos. Hemos clasificado todas las imágenes según la perspectiva aportada por Abreu, y hemos obtenido los siguientes resultados.

Géneros (informativos y opinativos) encontrados en tipografía y en offset

\begin{tabular}{|c|c|c|c|c|c|c|c|c|c|c|c|}
\hline \multirow{3}{*}{ Cabecera } & & \multicolumn{10}{|c|}{ Género en tipografía ( $\mathrm{T}$ ) y offset $(\mathrm{O})$} \\
\hline & & \multicolumn{2}{|c|}{ Fotonoticia } & \multicolumn{2}{|c|}{ Reportaje } & \multicolumn{2}{|c|}{ Ensayo } & \multicolumn{2}{|c|}{ Editorial } & \multicolumn{2}{|c|}{ Fotomancheta } \\
\hline & & $T$ & 0 & $T$ & 0 & $T$ & 0 & $T$ & 0 & $T$ & 0 \\
\hline \multirow[b]{2}{*}{ El Día } & Recuento & 20 & 32 & 0 & 4 & 0 & 0 & 0 & 5 & 0 & 0 \\
\hline & $\%$ (de cabecera) & 13.1 & 12 & 0 & 0.1 & 0 & 0 & 0 & 0.1 & 0 & 0 \\
\hline \multirow[b]{2}{*}{ Diario de Las Palmas } & Recuento & 13 & 8 & 10 & 0 & 1 & 0 & 1 & 0 & 10 & 36 \\
\hline & $\%$ (de cabecera) & 5.3 & 2.7 & 4 & 0 & 0.4 & 0 & 0.4 & 0 & 4 & 12 \\
\hline \multirow[b]{2}{*}{ Total } & Recuento & 33 & 40 & 10 & 4 & 1 & 0 & 1 & 5 & 10 & 36 \\
\hline & $\%$ (total) & 8.2 & 7.1 & 2.5 & 0.7 & 0.2 & 0 & 0.2 & 0.9 & 2.5 & 6.4 \\
\hline
\end{tabular}


Subgéneros informativos encontrados en tipografía y en offset

\begin{tabular}{|c|c|c|c|c|c|c|c|c|c|c|c|c|c|}
\hline \multirow{3}{*}{ Cabecera } & & \multicolumn{12}{|c|}{ Subgénero en tipografía (T) y offset (O) } \\
\hline & & \multicolumn{2}{|c|}{ En noticia } & \multicolumn{2}{|c|}{ Reportaje } & \multicolumn{2}{|c|}{ Entrevista } & \multicolumn{2}{|c|}{ Reseña } & \multicolumn{2}{|c|}{ Crónica } & \multicolumn{2}{|c|}{ Encuesta } \\
\hline & & $\mathbf{T}$ & 0 & $\mathbf{T}$ & 0 & $\mathbf{T}$ & 0 & $\mathbf{T}$ & 0 & $\mathbf{T}$ & 0 & $\mathbf{T}$ & 0 \\
\hline \multirow[b]{2}{*}{ El Día } & Núm & 40 & 39 & 16 & 31 & 14 & 25 & 3 & 6 & 1 & 21 & 1 & 7 \\
\hline & $\%$ * & 26.1 & 14.7 & 10.5 & 11.6 & 9.1 & 9.4 & 2 & $\overline{2.3}$ & 0.6 & 2.6 & 0.6 & 2.6 \\
\hline \multirow[b]{2}{*}{$D L P$} & Núm & 71 & 52 & 34 & 30 & 32 & 30 & 38 & 2 & 0 & 57 & 0 & 24 \\
\hline & $\%^{*}$ & 28.7 & 17.4 & 13.8 & 10 & 13 & 10 & 15.4 & 0.7 & 0 & 19.1 & 0 & 8 \\
\hline \multirow[b]{2}{*}{ Total } & Núm & 111 & 91 & 50 & 61 & 46 & 55 & 41 & 8 & 1 & 78 & 1 & 31 \\
\hline & $\begin{array}{l}\% \\
\text { (total) }\end{array}$ & 27.7 & 16.1 & 12.5 & 10.8 & 11.5 & 9.7 & 10.2 & 1.4 & 0.2 & 13.8 & 0.2 & 5.5 \\
\hline
\end{tabular}

${ }^{\text {* }}$ Porcentaje sobre el total de fotos de esa cabecera

\section{Subgéneros opinativos encontrados en tipografía y en offset}

\begin{tabular}{|c|c|c|c|c|c|}
\hline \multirow{3}{*}{ Cabecera } & \multirow{2}{*}{} & \multicolumn{4}{|c|}{$\begin{array}{c}\text { Subgénero en tipografía } \\
\text { (T) } \mathbf{y} \text { offset (O) }\end{array}$} \\
\cline { 3 - 6 } & & \multicolumn{2}{|c|}{ Editorial } & \multicolumn{2}{|c|}{ Artículo } \\
\cline { 3 - 6 } & $\mathbf{T}$ & $\mathbf{O}$ & $\mathbf{T}$ & $\mathbf{0}$ \\
\hline \multirow{2}{*}{ El Día } & Núm & 0 & 1 & 7 & 1 \\
\hline \multirow{2}{*}{ DLP } & $\%^{*}$ & 0 & 0.4 & 4.6 & 0.4 \\
\hline \multirow{3}{*}{ Núm } & 1 & 0 & 2 & 9 \\
\hline & $\%^{*}$ & 0.4 & 0 & 0.8 & 3 \\
\hline & Núm & 1 & 1 & 9 & 10 \\
\hline & $\begin{array}{c}\% \\
\text { (total) }\end{array}$ & 0.2 & 0.2 & 2.2 & 1.5 \\
\hline
\end{tabular}

\section{* Porcentaje sobre el total de fotos de esa cabecera}

Los resultados nos muestran que el empleo de las fotografías (tanto antes como después de la llegada del offset) se centra en unos pocos géneros, mientras que los demás son testimoniales o inexistentes. Predomina el uso de las fotografías como subgénero, es decir, que son un complemento del texto, mientras que el empleo de imágenes como género (constituyen el centro de la noticia, que se organiza en torno a ella) es más aislado. La imagen complemento de una noticia, como subgénero, es lo más frecuente ( $27.7 \%$ en tipografía y $16.1 \%$ en offset respectivamente). Le siguen en frecuencia la fotografía complemento de un reportaje y de entrevista. Los géneros fotográficos como tal apenas se utilizan, exceptuando las fotonoticias $(8.2 \%$ y $7.1 \%$ en tipografía y offset respectivamente). La presencia de fotografías en géneros o subgéneros de opinión es muy poco frecuente, destacando entre ellos la foto mancheta, bastante utilizada en Diario de Las Palmas.

La implantación del sistema offset no parece haber modificado de manera importante la distribución de las fotografías por géneros. Se encuentra, no obstante, un menor porcentaje de fotografías acompañando a noticias (como subgénero) y un aumento considerable de las fotografías que acompañan a las crónicas (también como subgénero), merced al importante incremento en este tipo de fotos que se observa en Diario de Las 
Palmas con la llegada del offset. La reseñas experimentan, en cambio, un notable descenso, del que es responsable Diario de Las Palmas.

Hay que volver a recordar que la comparación entre periódicos no es suficientemente sólida, al existir 5 años de diferencia entre uno y otro, y son las variaciones producidas al llegar el offset (dentro de cada periódico) lo que nos interesa.

\subsection{Actualidad de las fotografías}

La impresión offset no produjo en el período analizado un aumento en el número de fotos recientes (tomadas el día anterior, o dos días antes) que se publicaban en el periódico. Al eliminarse el penoso proceso del fotograbado e insertarse los fotolitos, planteamos como hipótesis que se colocarían fotos más actuales, y que con ello se demandarían más imágenes a los fotógrafos. Al llevar a cabo la prueba de chi-cuadrado de Pearson, en la que correlacionamos las variables "antigüedad de la foto" y "técnica empleada", considerando ambos periódicos, encontramos que $\alpha \leq 0,05$. Sin embargo, los residuos tipificados corregidos nos indican que no se puede correlacionar la llegada del offset con un mayor número de fotografías "recientes" publicadas. Paradójicamente, enco ntramos un residuo tipificado corregido $\geq \pm 1,96$ (significación estadística) en las fotos tomadas dos días antes de la publicación del periódico, pero en sentido inverso al esperado: con la técnica tipográfica se publicaron más fotos de dos días de antigüedad. Si analizamos los datos por periódicos, y no de manera global, encontramos que esta anomalía comentada (menor presencia de fotos de dos días de antigüedad tras la llegada del offset) se encuentra en Diario de Las Palmas y no en El Día. Esto se debe a que en la muestra en offset de Diario de Las Palmas no encontramos ninguna foto con dos días de antigüedad, frente a las 18 de la muestra de periódicos tirados en tipografía. De todos modos, estos datos deben ser manejados con mucha cautela, debido al elevado número de fotos de las que no pudo establecerse su antigüedad por no especificarse en el pie ni poder deducirse por el texto de la noticia.

Antigüedad de las fotografías publicadas en tipografía

\begin{tabular}{|c|c|c|c|c|c|c|}
\hline \multirow{4}{*}{ Cabecera } & & \multicolumn{4}{|c|}{ Antigüedad de la foto } \\
\cline { 2 - 7 } & & Ayer & $\begin{array}{c}\text { Antes de } \\
\text { ayer }\end{array}$ & $\begin{array}{c}\text { Una } \\
\text { semana o } \\
\text { menos }\end{array}$ & $\begin{array}{c}\text { Más de } \\
\text { una } \\
\text { semana }\end{array}$ & $\begin{array}{c}\text { No } \\
\text { valorable }\end{array}$ \\
\hline \multirow{3}{*}{ El Día } & Recuento & 24 & 3 & 0 & 0 & 106 \\
\cline { 2 - 7 } Diario de Las Palmas & $\begin{array}{c}\text { Porcentaje (de } \\
\text { cabecera) }\end{array}$ & 18.04 & 2.26 & 0 & 0 & 79.70 \\
\cline { 2 - 8 } & Recuento & 38 & 18 & 4 & 3 & 172 \\
\cline { 2 - 8 } & $\begin{array}{c}\text { Porcentaje (de } \\
\text { cabecera) }\end{array}$ & 16.17 & 7.66 & 1.70 & 1.27 & 73.19 \\
\cline { 2 - 8 } Total & Recuento & 62 & 21 & 4 & 3 & 278 \\
\cline { 2 - 7 } & Porcentaje (total) & 16.85 & 5.70 & 1.09 & 0.82 & 75.54 \\
\hline
\end{tabular}

\section{Antigüedad de las fotografías publicadas en offset}

\begin{tabular}{|c|c|c|c|c|c|c|}
\hline \multirow{2}{*}{ Cabecera } & & \multicolumn{5}{|c|}{ Antigüedad de la foto } \\
\cline { 3 - 7 } & & Ayer & $\begin{array}{c}\text { Antes de } \\
\text { ayer }\end{array}$ & $\begin{array}{c}\text { Una } \\
\text { semana o } \\
\text { menos }\end{array}$ & $\begin{array}{c}\text { Más de } \\
\text { una } \\
\text { semana }\end{array}$ & $\begin{array}{c}\text { No } \\
\text { valorable }\end{array}$ \\
\hline \multirow{2}{*}{ EI Día } & Recuento & 31 & 3 & 1 & 6 & 153 \\
\cline { 2 - 8 } & Porcentaje (de & 15.98 & 1.55 & 0.52 & 3.09 & 78.87 \\
\hline
\end{tabular}




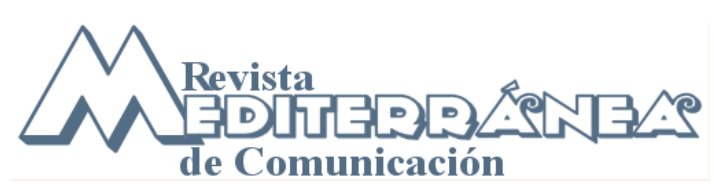

ISSN 1989-872X - Año2 (2011), pp. 125-142

\begin{tabular}{|c|c|c|c|c|c|c|}
\cline { 2 - 7 } Diario de Las Palmas & cabecera) & & & & 2 \\
\cline { 2 - 7 } & Recuento & 43 & 0 & 2 & 222 \\
\cline { 2 - 7 } & $\begin{array}{c}\text { Porcentaje (de } \\
\text { cabecera) }\end{array}$ & 15.99 & 0 & 0.74 & 0.74 & 82.53 \\
\cline { 2 - 7 } Total & Recuento & 74 & 3 & 3 & 8 & 375 \\
\cline { 2 - 7 } & Porcentaje (total) & 15.95 & 0.65 & 0.65 & 1.72 & 80.82 \\
\hline
\end{tabular}

\subsection{Procedencia de las fotos}

Para El Día, en agosto de 1975, un 54\% de las fotos no tenían atribución; un 8\% eran de agencia (AP-Europa Press); mientras que un $21 \%$ eran de algún fotógrafo colaborador. El $5 \%$ eran de archivo y el $12 \%$ no se atribuían por ser fotografías de publicidad. Con la llegada del offset, (análisis de octubre de 1975), disminuyó el número de fotos sin atribuir (32\%); un $11 \%$ eran de agencia, un $28 \%$ de fotógrafos, casi un $2 \%$ de archivo y cerca de un $27 \%$ fotos publicitarias.

Para Diario de Las Palmas, en abril de 1980, el 55\% de las fotos no tenía atribución; casi el $9 \%$ eran de agencia, más de un $30 \%$ procedían de algún fotógrafo y un $1 \%$ no eran encuadrables en nuestra clasificación, por proceder de algún particular o tener una atribución confusa. Un $11 \%$ de las fotos eran publicitarias, y ninguna foto se atribuyó al archivo. La llegada del offset no trajo consigo más fotos de archivo, pero sí se modificaron algunos porcentajes: Casi un 59\% no tenían atribución; algo más de un $4 \%$ eran de agencia; un $26.5 \%$ de fotógrafos y un $10 \%$, publicitarias.

Con estos resultados podríamos afirmar, siempre con precaución por la variable antes comentada de la estacionalidad, que en El Día se produjo un aumento en la cantidad de fotografías asociadas a la publicidad y que se redujo el número de fotos no atribuidas, además de aumentar moderadamente el porcentaje de fotos de agencia y las solicitadas a los fotógrafos. En Diario de Las Palmas parece claro que las fotos de archivo no se atribuían, dejando esta carencia en el pie de foto. El resto de los datos no permiten establecer conclusiones claras.

Uno de los fotógrafos consultados, de gran importancia para el periódico El Día en estos años ${ }^{9}$, afirma que con la agencia Efe, a lo largo de su carrera profesional, facturaba cada vez más imágenes. Con El Día, en cambio, el volumen fue siempre similar, y no notó un aumento en la petición de imágenes en los años centrales de la década de los 70 . El estudio, por tanto, no ofrece conclusiones sólidas en este punto.

\subsection{Fotoperiodismo / fotoilustración}

Siguiendo la clasificación sugerida por De Pablos (2003) hemos querido estudiar si la llegada del offset trajo consigo un aumento de las fotografías periodísticas frente a las meramente ilustrativas. En teoría, la posibilidad de poder publicar más fotos y más recientes debería haber estimulado a los responsables del periódico a utilizar mayor número de fotos periodísticas. Para De Pablos, la fotografía periodística, además de ser actual, ha de contener acción e información, y es la foto que debería tener mayor presencia en las páginas de los periódicos. La realidad es que, en la mayoría de las publicaciones periódicas predomina la fotografía ilustrativa, de carácter más atemporal, y más económica para el periódico (puede obtenerla del archivo, emplearla más de una 
vez...). La fotografía periodística es única, y no puede repetirse en sucesivas informaciones sin perder su valor.

Hemos encontrado en nuestra muestra que la foto periodística suele ser de agencia, y de acontecimientos que suceden fuera de las islas. Es decir, que, paradójicamente, un periódico local daba un mejor tratamiento visual a las noticias nacionales e internacionales que a aquéllas que suceden en las proximidades de la redacción. Por periódicos, (sin tener en cuenta si se imprimieron en tipografía o en offset) los resultados han sido los siguientes.

\section{Fotos periodísticas y fotos ilustrativas}

\begin{tabular}{|c|c|c|c|c|c|}
\hline \multirow{2}{*}{ Cabecera } & \multicolumn{2}{|c|}{ Fotos periodística s } & \multicolumn{2}{c|}{ Fotos ilustrativas } & \multirow{2}{*}{ Total } \\
\cline { 2 - 5 } & Número & $\%$ & Número & $\%$ & \\
\hline El Día & 71 & 21.39 & 261 & 78.61 & 332 \\
\hline Diario de Las Palmas & 127 & 25.30 & 375 & 74.70 & 502 \\
\hline Total & 198 & 23.74 & 636 & 76.26 & 834 \\
\hline
\end{tabular}

Si tenemos en cuenta ahora el sistema de impresión, obtendremos los siguientes resultados.

\begin{tabular}{|c|c|c|c|c|c|c|c|c|c|c|}
\hline \multirow{3}{*}{ Cabecera } & \multicolumn{5}{|c|}{ Tipografía } & \multicolumn{5}{|c|}{ Offset } \\
\hline & \multicolumn{2}{|c|}{ Periodísticas } & \multicolumn{2}{|c|}{ Ilustrativas } & \multirow[t]{2}{*}{ Tot } & \multicolumn{2}{|c|}{ Periodísticas } & \multicolumn{2}{|c|}{ Ilustrativas } & \multirow[t]{2}{*}{ Tot } \\
\hline & № & $\%$ & № & $\%$ & & № & $\%$ & № & $\%$ & \\
\hline El Día & 31 & 23.31 & 102 & 76.70 & 133 & 40 & 20.20 & 158 & 79.80 & 198 \\
\hline$D L P$ & 64 & 27.23 & 171 & 72.77 & 235 & 63 & 23.60 & 204 & 76.40 & 267 \\
\hline Total & 95 & 25.82 & 273 & 74.18 & 368 & 103 & 22.15 & 362 & 77.85 & 465 \\
\hline
\end{tabular}

\subsection{Representación visual de otras realidades geográficas}

La imagen tiene gran fuerza persuasiva, y contribuye con el texto a configurar ciertos encuadres, ciertos marcos de percepción de la realidad, sobre todo en aquellos asuntos sobre los que no tenemos una experiencia directa, como nos dice la teoría del framing ${ }^{10 .}$ En este apartado pretendemos conocer qué realidades geográficas se representan en las fotografías publicadas. Así, la imagen puede haber sido obtenida en un ámbito insular, provincial, regional, nacional, internacional... De manera especial, hemos intentado valorar la existencia del denominado "pleito insular" ¿Se mostraba la provincia de Las Palmas, y la isla de Gran Canaria, en las fotos de los periódicos tinerfeños? Y al revés, ¿se mostraba Tenerife y su provincia desde los periódicos grancanarios? Y, si se muestra, ¿se hace de manera equilibrada? También hemos pretendido cuantificar la presencia (o ausencia) visual de las llamadas islas periféricas (La Palma, La Gomera, El Hierro, Fuerteventura y Lanzarote), que tradicionalmente han venido sufriendo la "doble insularidad": además de su condición de islas, dependen de otras islas (las centrales) 
para multitud de cuestiones, entra las que podemos incluir la asistencia sanitaria especializada o la circulación de mercancías y personas hasta el territorio peninsular.

Leyendo el pie de foto (si lo había) y el texto que acompaña a las imágenes, hemos podido deducir su localización, es decir, dónde fue tomada. En ocasiones, y ante la falta de datos, hemos recurrido a nuestro conocimiento de la geografía ca naria para encuadrar la foto, pero esto ha sido la excepción y no la norma. Para el resto de los casos en que no hemos podido verificar la localización, hemos creado en la variable "lugar" el valor "desconocido". De esta manera, y analizando los dos periódicos en su conjunto (sabiendo que corresponden a épocas distintas) encontramos que sólo un 3,2\% de las fotos se pueden encuadrar en la categoría "regional", es decir, que pertenecen a alguna de las islas de la otra provincia (Santa Cruz de Tenerife para el Diario de Las Palmas y Las Palmas para El Día). Algo menos de la mitad corresponden a la isla donde se edita el periódico, y un $2 \%$ a otras islas de su provincia. Un $8,2 \%$ muestran escenas ocurridas en el resto de España y un $9,4 \%$ en otros países. Un $18 \%$ son de ubicación desconocida, y el resto corresponde a imágenes publicitarias, en las que hemos dejado en blanco la variable "lugar".

En los dos periódicos analizados, sin embargo, este fenómeno no tiene la misma magnitud. Desglosando los resultados por periódicos, observamos que El Día presenta resultados peores en cuanto a la representación visual de la provincia de Las Palmas (sólo un 2,1\%). Las islas periféricas de la provincia de Santa Cruz de Tenerife, no obstante, salen mejor paradas, con una frecuencia del 3,3\%. Diario de las Palmas, por contra, presenta un comportamiento mejor en cuanto a la representación de la provincia de Santa Cruz de Tenerife (4\%), pero peor en cuanto a la publicación de imágenes de Lanzarote o Fuerteventura: sólo un $0,7 \%$.

\subsection{Color}

El uso del color en las imágenes ha sido prácticamente nulo. Encontramos cinco imágenes en total que hacían algún uso del color, Todas ellas en monotono rojo. Tres de ellas en El Día, concretamente el 9 de octubre de 1975 (ya con la imprenta offset). Se trata de tres fotografías en un reportaje sobre lgueste de San Andrés, pero parece tratarse de un error o una prueba, pues no se entiende de otra manera ese monotono carente de función estética alguna. También encontramos un monotono rojo el 17 de junio del 80 (también en offset) en primera página de Diario de Las Palmas, esta vez sí que de manera intencional, que muestra la nueva estación de satélites de Maspalomas. Pese a ser más laborioso, la tipografía también permitía usar el color, y de hecho también encontramos un monotono rojo en una imagen tirada en tipografía en el periódico de Las Palmas de 30 de abril de 1980, página 9, que ilustra un reportaje sobre la situación laboral de las mujeres.

No obstante, el color (principalmente rojo y azul) sí que se utilizaba de manera relativamente frecuente como recurso visual en la cabecera, en filetes, recuadros, corondeles... En nuestra muestra no hemos encontrado para el diario El Día este tipo de uso del color hasta que llegó la imprenta offset. A partir de este momento, sí empezó a imprimir su cabecera (y otros elementos visuales) en color azul. Diario de Las Palmas, por el contrario, ya utilizaba el color como elemento visual (especialmente el rojo) con su vieja rotativa tipográfica. 


\section{Conclusiones}

La llegada del sistema de impresión offset trajo consigo ciertos cambios en el periódico, que afectaron gradualmente a campos tan diversos como la fotografía o los procesos de composición y reproducción. Estos cambios, sin embargo, no supusieron una revolución, en el sentido de alterar rápidamente las rutinas de producción o la composición de las páginas. Más bien al contrario, con la llegada de la nueva tecnología se continuaron haciendo casi las mismas cosas, pero de una manera diferente. Las rutinas de producción de la información, las limitaciones económicas, o el contexto sociocultural pueden ser más importantes en el producto periodístico que la llegada de una nueva tecnología. La confección de un periódico más atractivo, la colocación de al menos una foto por página, $\mathrm{y}$, en general, el desarrollo de la cultura visual fue un proceso muy lento que no se materializó de un día para otro. Como sostienen Almirón y Jarque (2008), la tecnología por sí sola no va a poder ser el motor de ningún cambio, y sostener lo contrario es construir un discurso míticos, ahistórico, falto de conexión con la realidad y con el entorno político, social y económico.

En Canarias, la transición al offset se produjo en dos tiempos: un primer tiempo, representado por el periódico El Día y otro, cinco años más tarde, llevado a cabo por cabeceras como La Provincia y Diario de Las Palmas (estas dos últimas cabeceras se imprimían en la misma rotativa offset, y se pasaron al nuevo sistema con un mes de diferencia). El Día apostó mucho antes por una tecnología que se demostró muy efectiva para aumentar el volumen de negocio, tanto por la preferencia del público hacia un papel "más limpio" "como por las mayores posibilidades para la impresión.

Debido a esta diferencia temporal hemos tratado de apuntar tendencias que se pusieron de manifiesto con el cambio de rotativa, y verificar si, a pesar de estos 5 años transcurridos, esas tendencias fueron equiparables en ambas cabeceras. Así, nos preguntamos cuestiones como si aumentó el número de fotografías publicadas, su tamaño, si se produjeron cambios en el diseño del periódico, etc. Por otro lado, pretendíamos averiguar si se producirían cambios sustanciales con la llegada del offset en sólo un mes, o deberíamos esperar más tiempo para valorar los cambios. De Pablos ${ }^{12}$, desde la dirección de El Día, apostó decididamente por las fotos de gran tamaño y el uso del color, pues antes de su llegada no se habían producido apenas cambios. Si bien es cierto que el diario tinerfeño fue de los primeros del país en utilizar el color con cierta asiduidad, también lo es que estas apuestas tuvieron lugar a partir de 1979, cuando la impresora offset ya llevaba 4 años funcionando ${ }^{13}$. A pesar de que el cambio tuvo su importancia, las rutinas periodísticas provocaron que no se aprovechasen de inmediato todas las posibilidades del nuevo sistema. No obstante, se produjeron modificaciones de interés en aspectos como el formato, y el número de las fotos. Los aspectos económicos y laborales de periodistas y fotógrafos tampoco experimentaron cambios relevantes. La situación de los fotógrafos de prensa era y continuó siendo especialmente difícil: no tenían relación contractual con los periódicos y actuaban como autónomos a los que se pagaba (poco) por cada fotografía publicada.

Las nuevas rotativas precisaban papel con medidas diferentes a las viejas. En el caso de El Día se produjo una reducción en el formato, mientras que en Diario de las Palmas el formato aumentó ligeramente. A diferencia del contexto anglosajón, el tamaño sábana o 
tabloide no se asocian en nuestro país, respectivamente, a "prensa seria" o "prensa sensacionalista". La razón es que, debido a las bajas tasas de alfabetización que se arrastraban históricamente, el segundo tipo de prensa nunca se desarrolló, y el tamaño del periódico respondía más al papel de que se disponía o a las imposiciones de las rotativas.

Al menos inicialmente, no se produjo un aumento en el tamaño de las fotos publicadas, pero sí en su número, pues el proceso era mucho menos fatigoso que en el anterior sistema, basado en el fotograbado. Por las fuentes orales (especialmente gracias a Juan Hernández) y la bibliografía antes mencionada, sabemos que el proceso para incluir imágenes era más rápido $\mathrm{y}$, sobre todo, menos laborioso, que el clásico sistema del fotograbado (o el Foto-Lathe ${ }^{14}$ de El Día). Nuestros hallazgos parecen confirmar la afirmación de las fuentes orales ${ }^{15}$ de que "con el offset se hacían más cantidad de fotografías; el fotolito era mucho más cómodo". La misma fuente señala, además, que "en la época de la tipografía, con la técnica del fotograbado, se podían hacer un máximo de 4 ó 5 fotos en una tarde". A pesar de que el sistema de fotograbado (tanto por procesos químicos como, posteriormente, físicos, con el Foto-Lathe) permite hacer fotos de gran tamaño, la realidad es que lo pesado del proceso y las limitaciones de personal a su cargo provocaban que la tendencia fuese a poner fotos pequeñas, pues así se podían colocar mayor número de imágenes en una sola prensas de fotograbado. Juan Hernández afirma que, antes de introducir el Foto-Lathe, "las prensas de fotograbado permitían como máximo dos fotografías de $13 \times 18$ ", o más si eran más pequeñas. El incremento porcentual en el número de fotos publicadas tras el primer mes con la nueva imprenta fue significativamente mayor en El Día que en Diario de Las Palmas.

Habitualmente las fotos de un periódico proceden de una agencia, de un fotógrafo, del archivo (aunque, a su vez, las fotos del archivo proceden de un fotógrafo o de una agencia) o de un particular o aficionado a las fotografías. La procedencia debe de especificarse en el pie de foto (De Pablos, 2003). Al aumentar el número de fotografías que se publicaban, podemos pensar que se produjeron cambios en la procedencia de éstas: quizá se pidieran más fotos a los fotógrafos, o se compraban más a las agencias, o se repitieran más fotos del archivo. Según nuestro estudio, El Día aumentó la cantidad de fotografías asociadas a la publicidad y redujo el número de fotos no atribuidas, además de aumentar de manera muy moderada el porcentaje de fotos de agencia y las solicitadas a los fotógrafos. En Diario de Las Palmas, en cambio, la llegada de la nueva tecnología no provocó cambios relevantes en la distribución del origen de las fotografías. La fotografía publicitaria estaba ya consolidada en el viejo periódico tirado en tipografía.

La fotografía de prensa en los dos periódicos estudiados tiende a infrarrepresentar a la isla "rival" (Gran Canaria para Tenerife y viceversa). Además, las islas periféricas también están infrarrepresentadas, independientemente de que pertenezcan a la provincia de edición del periódico o no. De este modo, y sin entrar a valorar el contenido de las fotos, podemos afirmar que a través de las imágenes se crea un marco de percepción de la realidad donde lo más destacado es lo que sucede en la propia isla. Además, se "esconde" lo que sucede en las islas periféricas y en la "otra" isla central (Tenerife o Gran Canaria, según el periódico). ¿Se puede hablar de ánimo pleitista en la colocación de las fotos? No nos atrevemos a tanto, pero en cualquier caso podemos afirmar con cierta base que: 
a.- Las islas periféricas son marginadas en las fotografías de los dos periódicos. Se establece un circuito informativo en el que es noticia lo que sucede en las dos islas centrales.

b.- La "otra" isla central también queda fuera de la visión de los lectores.

En cuanto el uso del color, la llegada del offset (pese a las posibilidades que brindaba) no aumentó de manera importante su empleo. La causa más probable, según las fuentes orales, pudo haber sido el precio de las tintas.

Se produjeron, en resumen, cambios muy discretos en las formas del periódico, mientras que las rutinas y los contenidos continuaron siendo iguales. Las empresas periodísticas siguieron motivadas por el afán recaudatorio y no se produjeron mejoras en las condiciones laborales de los trabajadores más castigados del periódico: los fotógrafos de prensa, que debieron continuar con los reportajes fotográficos de bodas, bautizos y comuniones como fuente principal de ingresos. Conviene, pues, desmitificar y recontextualizar el papel de esta nueva tecnología, que en muchas ocasiones ha sido sobrevalorado en la bibliografía académica.

\section{Bibliografía}

Abreu, Carlos (1998): Los géneros periodísticos fotográficos. Barcelona: Cims.

Almiron, N. y Jarque, J. M. (2008): El mito digital: discursos hegemónicos sobre internet y periodismo. Barcelona: Anthropos.

Ardèvol, A. (2008): "La inmigración, en la fotografía de prensa de Canarias", en Revista Latina de Comunicación Social, 63 (2008), Universidad de La Laguna, pp. 409-417. Recuperado http://www.revistalatinacs.org/08/34 79154 fotoperiodismo/Alberto Ardevol.html [consulta 11 de mayo 2011].

Caballo, D. (2003): Una historia de la fotografía en prensa, en Fotoperiodismo y edición: Historia y límites jurídicos. Madrid: Universitas.

De Pablos, J. M. (1993): Del plomo a la luz. Santa Cruz de Tenerife: Idea

- (1997): Amarillo en prensa. Madrid: Idea.

- (2001). El periodismo herido: Estudios que delatan divorcio entre prensa $y$ sociedad. El País, como referente. Madrid: Foca.

- (2003). "Siete leyes del fotoperiodismo", en Caballo, D. (coord.), Fotoperiodismo y edición: Historia y límites jurídicos. Madrid: Universitas, pp. 235-314.

Rodríguez, E. y Gómez, R. (2003): “Una historia de la fotografía en la prensa”, en Caballo, D. (coord.), Fotoperiodismo y edición: Historia y límites jurídicos. Madrid: Universitas, pp. 17-96.

Tankard, J. W: "The empirical approach to the study of media framing" (2001). Cita recogida de Muñiz, C. e Igartúa, J. J (2004): "Encuadres noticiosos e inmigración. Un análisis de contenido de la prensa y televisión españolas”, en Zer, 16 (2004), pp. 87-104. 


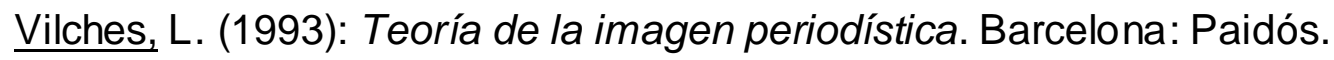

Villa, M. I. (2008): "Particularidades de la fotografía informativa en los medios online españoles". Revista Latina de Comunicación Social, 63 Disponible en la siguiente URL: http://www.ull.es/publicaciones/latina/08/25 37 UAB/Maria Isabel Villa.html [consulta 1 de mayo 2011].

Yanes, J. A. (2003): Historia del Periodismo Tinerfeño, 1758-1936. Tenerife: Centro de la Cultura Popular Canaria.

Zurita, R. (2003): Tenerife con olor a tinta: rudimentos de las artes gráficas: de la tipografía al offset. Santa Cruz de Tenerife: Gráficas Tenerife.

\section{Notas}

\footnotetext{
${ }^{1}$ Los tiempos de exposición que necesitaba la película fotográfica (o las superficies análogas que hacían la función de negativo) eran, en un principio, enormes, lo que limitaba mucho el tipo de imágenes que se podían tomar. Además, los equipos eran, en principio, pesados y complejos, lo que convertía al fotógrafo en porteador de su material, con las restricciones que esto le provocaba.

2 De Pablos (1993: 135-136), por ejemplo, afirma que "en tiempos del plomo era muy arriesgado dar fotos grandes, en el offset eso pasó a la historia, de modo que la definición de las imágenes impresas se aproximaba bastante a los originales de los que había copiado. [...] El offset podía dar fotos grandes, tan grandes como se quisiera, con la seguridad de obtener una muy aceptable calidad de reproducción. Como segunda cuestión, en los periódicos en offset se podría establecer páginas gráficas, como no se había hecho con anterioridad, como era impensable en los años 70 con rotativas tipográficas".

${ }^{3}$ Aunque situados en un contexto posterior (el digital), vale la pena consultar la obra de Almiron y Jarque (2008) acerca del mito tecnológico. El discurso sobre la capacidad redentora de las nuevas tecnologías (ellos hablan de internet y la era digital, pero se podría extrapolar a la llegada de la imprenta offset) no se corresponde con la realidad, sino, generalmente, con los intereses del mercado capitalista. Existe alrededor de cada nueva tecnología una serie de determinantes económicos, políticos y sociales que resultan determinantes para permitir o no cualquier cambio en lo que realidad importa: las condiciones de vida de los seres humanos. Al igual que sucediera con el ferrocarril en el siglo XIX, el telégrafo, la electricidad, el teléfono o la radio, cada nueva tecnología promete traer consigo una mayor dosis de igualdad, de justicia social, de democracia y de toma de poder por parte de la ciudadanía. Este discurso sólo puede sostenerse negando la historia, pues ninguna de las anteriores tecnologías fue capaz de cumplir su rosario de promesas de un mundo mejor. Ciñéndonos a nuestro estudio, la llegada de esta tecnología de impresión se topó, en su inicio, con numerosas resistencias que impidieron aprovechar al máximo sus posibilidades: rutinas de producción de información, plantilla escasa, inexistencia de fotógrafos en plantilla, escasa formación visual de periodistas y encargados de la composición... De manera que los primeros años de impresión offset originaron un periódico más limpio (no manchaba las manos) pero con diseño y composición muy similares.

${ }^{4}$ Aunque lo habitual fue abandonar el plomo con la llegada del offset, existía la posibilidad (y en algunos talleres se empleó en la fase de transición) de fotografiar una prueba impresa compuesta con el antiguo sistema tipográfico, bas ado en el plomo (Zurita, 2003: 31).

5 Entrevista con Ricardo Acirón Royo, catedrático de Periodismo de la Universidad de La Laguna. La Laguna, marzo de 2010.

6 Diario de Las Palmas, 2 de mayo de 1980, p. 2.

7 Hemos utilizado una metodología muy similar a la empleada para nuestro trabajo sobre inmigración en la fotografía de prensa de Canarias (Ardèvol, 2008).

${ }^{8}$ Para ello, tomamos en consideración la propuesta de Abreu (1988).
} 
${ }^{9}$ Entrevista con Antonio García Rueda, fotógrafo que trabajó para Efe, El Día y el Ayuntamiento de La Laguna en los años 60, 70 y 80. La Laguna, julio de 2010.

${ }^{10}$ Tankard (2001) utiliza el símil del marco fotográfico para explicar esta teoría, de manera que los medios constituirían un marco que delimitaría la realidad y nos permitiría percibir una parte de ella. Los medios no funcionarían como determinantes absolutos de nuestras perspectivas, opiniones y representaciones de la realidad, como pretendía la teoría de la aguja hipodérmica, pero sí nos proporcionarían un punto de vista, una atalaya desde donde contemplar la realidad, magnificando algunos de sus aspectos y minimizando $u$ ocultando otros. La prensa, como el resto de los medios de comunic ación, privilegiaría con su encuadre la saliencia de ciertos elementos de la realidad en detrimento de otros, y provocaría en sus lectores la aprehensión de una realidad deformada y estereotípica. Además, el encuadre es la idea organizadora de la historia, es el punto central en torno al que se organiza la información, puesto que un conjunto de hechos aislados sin conexión no configura una noticia.

${ }^{11}$ A principios de los 90, en Inglaterra, los diarios tirados en offset se anunciaban en TV con este lema: "We don't print on your hand, we print on paper" (no imprimimos tu mano, imprimimos el papel). En De Pablos, 1993: 19.

${ }^{12}$ Entrevista con José Manuel de Pablos Coello, catedrático de Periodismo de la Universidad de La Laguna. La Laguna, noviembre de 2010.

"[...] El 1 de junio de 1982, la agencia Efe transmitió desde Madrid especialmente para el periódico de Tenerife [EI Día] las tres copias de la selección de color de lo que al día siguiente, 2 de junio, de 1982, sería la primera telefoto en color interior - de origen Efe- distribuida y publicada en España [las anteriores eran de $A P$ o de otras agencias. Efe adquirió los equipos para hacer color propio en telefotos y ensayó con El Día, único periódico que recibía y publicaba telefotos en color". (De Pablos, 1993: 18).

${ }^{14}$ A finales de los años 60 se incorporó en El Día la tecnología del "Foto-Lathe", que permitía confeccionar fotograbados sin emplear productos químicos. La máquina tenía un torno y dos tambores: uno contenía la foto a grabar y otro la plancha de zinc. A través de una célula fotoeléctrica, la máquina leía la foto (de manera similar a un escáner) y, a través de un buril manejado por un equipo electrónico, se hacía el grabado. La calidad de este sistema no fue nunca muy alta. De Pablos, 1993: 12.

${ }^{15}$ Entrevista con Juan Hernández. 